\title{
DAYA TAHAN AEROBIK PADA ATLET SEKOLAH SEPAKBOLA USIA 14-16 TAHUN
}

\author{
Rika Sepriani $^{1}$, Rezki Kurnia Rahman ${ }^{2}$ \\ ${ }^{1}$ Program Studi Pendidikan Jasmani Kesehatan dan Rekreasi, Fakultas Ilmu Keolahragaan, \\ Universitas Negeri Padang. Jalan Prof. Dr. Hamka Air Tawar Barat, Padang, 25132, Indonesia. \\ ${ }^{2}$ Program Studi Ilmu Keolahragaan, Fakultas Ilmu Keolahragaan, Universitas Negeri Padang. Jalan \\ Prof. Dr. Hamka Air Tawar Barat, Padang, 25132, Indonesia.
}

\section{E-mail: rikasepriani@fik.unp.ac.id ${ }^{1}, \underline{\text { Rezkikurnia2610@gmail.com }}{ }^{2}$}

\begin{abstract}
Abstrak
Tujuan penelitian ini untuk mengetahui tingkat kemampuan daya tahan aerobik atlet Sekolah Sepakbola Global usia 14-16 tahun kota Payakumbuh. Penelitian ini menggunakan pendekatan penelitian deskriptif. Populasi penelitian ini berjumlah 25 atlet. Teknik pengambilan sampel dilakukan dengan cara total sampling yaitu semua populasi dijadikan sampel dengan jumlah 25 atlet. Pengumpulan data menggunakan instrumen Yo-yo Intermittent Recovery Test. Teknik analisis data yang digunakan adalah teknik statistik deskriptif dengan perhitungan persentase. Hasil penelitian menunjukkan adalah 3 orang (12\%) tergolong sedang, 12 orang (48\%) tergolong kategori kurang, dan 10 orang $(40 \%)$ memiliki daya tahan aerobik tergolong kurang sekali. Simpulan dari penelitian ini yaitu tingkat kemampuan daya tahan aerobik atlet Sekolah Sepakbola Global usia 14-16 tahun kota Payakumbuh tergolong dalam kategori kurang sekali.
\end{abstract}

Kata Kunci : Daya tahan aerobic

\section{AEROBIC ENDURANCE ON SCHOOL FOOTBALL ATLETES AGES 14-16 YEARS OLD}

\begin{abstract}
The purpose of this research is to determine the level of aerobik endurance capability athletes global football school age 14-16 years old Payakumbuh city. This reseach used descriptive research approach. Population of this reseach is amounted 25 athletes. The technique of taked sampling is done by total sampling that all the population sampled with the number of 25 athletes. The data collection using by instrument yo-yo intermitten recovery test. Data analysis technique used is descriptive statistic technique with percentage counting. The results of this research is showed that 3 peoples (12\%) were classified as moderate, 12 peoples (48\%) were classified as less, and 10 peoples $(40 \%)$ had aerobic endurance classified as poor. Conclusion of this reseach is the endurance ability of aerobic athletes global football age 14-16 years old Payakumbuh city is classified in poor cotegory.
\end{abstract}

\section{Keyword : Aerobik endurance}

\section{A. Pendahuluan}

Sepak bola adalah olahraga yang dimainkan dengan cara menyepak yang bertujuan untuk memasukkan bola sebanyak mungkin ke gawang lawan dan menjaga gawang dari kebobolan (Muhajir dalam Santoso, 2014:42). Menurut Yulifri (2012:25), "Permainan sepak bola merupakan suatu kegiatan bermain yang sangat kompleks". Artinya banyak unsur keterampilan yang mempengaruhi permainan sepak bola itu sendiri seperti: keterampilan teknik, taktik, dan mental sangat dibutuhkan dalam permainan sepak bola dan bahkan menjadi salah satu penentu dalam keberhasilan permainan sepak bola. Untuk menjadi seorang atlet sepak bola yang berprestasi, keterampilan teknik dasar sepak bola harus dikuasai di samping unsur penting yang lain seperti kondisi fisik, taktik, dan mental.

Kondisi fisik yang merupakan komponen yang paling dasar dalam setiap olahraga untuk dapat mengembangkan komponen teknik, taktik, dan mental dengan baik. Menurut Grosser dalam Syafruddin (2016:54), "Kondisi fisik yang diperlukan dalam olahraga meliputi 
: (1) daya tahan, (2) kecepatan, (3) kelentukan, dan (4) kekuatan". Melihat pada kesanggupan seorang atlet sepak bola untuk melakukan tugas gerak yang banyak dan dalam waktu yang relatif lama, unsur daya tahan merupakan salah satu faktor yang sangat mempengaruhi keberhasilan atlet sepak bola di samping unsur kondisi fisik lainnya. Kualitas daya tahan yang baik sangat perlu dimiliki oleh setiap atlet sepak bola dalam menghadapi sebuah pertandingan ataupun turnamen. Jika atlet memliki daya tahan yang baik, maka atlet tersebut tidak akan mengalami kelelahan yang berarti ketika menjalani latihan atau pertandingan. Secara umum satu pertandingan sepak bola dimainkan dalam waktu 2 x 45 menit ( Luxbacher, 2011:2). Artinya, permainan sepak bola dimainkan dalam dua babak dengan waktu normal 90 menit (1,5 jam). Dengan waktu yang cukup lama tersebut akan mustahil rasanya atlet sepak bola bisa menjaga konsistensi penampilannya di dalam pertandingan apabila dia tidak memiliki kondisi fisik, terutama daya tahan aerobik yang baik.

Sesuai hasil pengamatan di lapangan dan wawancara penulis dengan pelatih Sekolah Sepak Bola Global kota Payakumbuh, bahwasanya atlet pada beberapa pertandingan sebelumnya sering mengalami penurunan performa pada saat melakukan pertandingan, hal ini terlihat pada hasil pertandingan yang mereka jalani, pada pertandingan pertama Sekolah Sepak Bola Global kalah 0-2, pertandingan kedua kalah 4-0, pertandingan ketiga mereka di tahan imbang 1-1 dan pada pertandingan terakhir mereka kalah 0-1. Banyak faktor permasalahan yang diduga menyebabkan penurunan performa atlet yang mengakibatkan mereka sering kalah dalam setiap pertandingan.

Salah satu faktor yang diduga mempengaruhi penuruna peforma atlet adalah kondisi fisik. Daya tahan aerobik merupakan salah satu dari komponen dari kondisi fisik. Daya tahan aerobik berhubungan dengan kemampuan jantung dan paru dalam memompa oksigen secara maksimal ke seluruh bagian tubuh. Menurut Bafirman (2010:34), "Daya tahan aerobik adalah kesanggupan melakukan kerja terus menerus selama mungkin dalam kondisi aerobik". Dalam kondisi aerobik pekerjaan dilakukan dengan intesitas rendah dengan waktu yang lama, yang lebih dari 5 menit. Menurut Umar (2014:13), "Aerobik adalah proses metabolisme energi dengan menggunakan oksigen". Kualitas daya tahan paru dan jantung dinyatakan dengan $\mathrm{VO}_{2} \mathrm{Max}$, yakni banyaknya oksigen maksimum yang dapat dikonsumsi dalam satuan $\mathrm{ml} / \mathrm{kg} / \mathrm{menit}$ (Irianto,2006:28). Tingkat daya tahan aerobik tiap-tiap atlet berbeda-beda, hal ini dipengaruhi oleh berbagai faktor,misalnya: keturunan, umur, pola hidup,latihan, lingkungan, status gizi dan teknologi (Deswandi,2015:19--23).

Dari permasalahan yang uraikan di atas, penulis bermaksud untuk mengetahui informasi tentang kemampuan kondisi fisik yang memfokuskan pada daya tahan aeobik. Untuk mengetahui tentang kemampuan daya tahan aerobik atlet Sekolah Sepakbola Global usia 14-16 tahun kota Payakumbuh perlu melakukan tes dan pengukuran terhadap kemampuan daya tahan aerobik setiap atlet menggunakan instrumen yo-yo intermittent recovery test yang belum pernah dilakukan sebelumnya. Karena pentingnya kemampuan daya tahan aerobik dalam permainan sepak bola, maka peneliti merasa tertarik mengadakan penelitian ini.

\section{B. Metode Penelitian}

Jenis penelitian ini tergolong pada jenis penelitian kuantitatif dengan menggunakan teknis analisis deskriptif, yang bertujuan untuk menggunakan sesuatu apa adanya. Sebagaimana yang dikemungkakan Suwirman (2015:38), "Penelitian deskriptif adalah penelitian yang bertujuan untuk membuat penyanderaan secara sistematis, faktual dan akurat mengenai fakta-fakta dan sifat-sifat populasi tertentu". Dalam penelitian deskriptif tidak perlu mencari atau menerangkan saling hubungan, mengajukan dan menguji hipotesis. Populasi dalam penelitian ini adalah atlet sekolah sepakbola Global kota Payakumbuh usia 14-16 tahun sebanyak 25 orang atlet. Karena jumlah sampel 
yang sama dengan jumlah populasi, maka pengambilan sampel dilakukan dengan teknik total sampling. Teknik pengambilan data menggunakan tes dan pengukuran kemampuan $\mathrm{VO}_{2} \mathrm{Maks}$ dengan instrumen yo-yo intermittent recovery test yang bertujuan untuk mengukur tingkat efisiensi fungsi jantung dan paru paru yang ditunjukkan melalui pengukuran ambilan oksigen maksimum ( $\left.\mathrm{VO}_{2} \mathrm{Max}\right)$.

Tabel Distribusi Data Daya Tahan Aerobik.

\begin{tabular}{|c|c|c|c|c|}
\hline \multirow[b]{2}{*}{ NO } & \multirow[b]{2}{*}{ Kelas Interval } & \multicolumn{2}{|c|}{ Frekuensi } & \multirow[b]{2}{*}{ Kategori } \\
\hline & & $\begin{array}{c}\text { Absolut } \\
\text { (Fa) }\end{array}$ & $\begin{array}{c}\text { Relatif } \\
\text { (Fr) }\end{array}$ & \\
\hline 1 & $>61,60$ & 0 & $0 \%$ & Sempurna \\
\hline 2 & $59,58-61,60$ & 0 & $0 \%$ & Baik Sekali \\
\hline 3 & $58,24-59,25$ & 0 & $0 \%$ & Baik \\
\hline 4 & $54,88-57,90$ & 3 & $12 \%$ & Sedang \\
\hline 5 & $51,52-54,54$ & 12 & $48 \%$ & Kurang \\
\hline 6 & $<51,52$ & 10 & $40 \%$ & Kurang Sekali \\
\hline \multicolumn{2}{|r|}{ Jumlah } & 25 & $100 \%$ & \\
\hline \multicolumn{2}{|r|}{ Rata-rata } & 51,44 & & \\
\hline \multicolumn{2}{|c|}{ Standar Deviasi } & 2,83 & & \\
\hline
\end{tabular}

Berdasarkan tabel distribusi frekuensi di atas, dari 25 orang atlet adalah 3 orang (12\%) memiliki daya tahan aerobik 54,88-57,90 tergolong sedang, 12 orang (48\%) memiliki daya tahan aerobik 51,52-54,54 tergolong kategori kurang, dan 10 orang (40\%) memiliki daya tahan aerobik $<51,52$ tergolong kurang sekali. Sedangkan untuk kategori sempurna, baik sekali, dan baik tidak ada (0\%). Berdasarkan data kelompok tersebut rata-rata hitung (mean) 51,44 tergolong dalam kategori kurang sekali dan simpangan baku (standar deviasi) 2,83 .

\section{Pembahasan}

Daya tahan aerobik adalah suatu kemampuan tubuh untuk mendapatkan oksigen yang dikirim ke otot-otot atau sel - sel sebagai bahan bakar pada waktu melakukan aktifitas serta dapat dikerjakan oleh sistem aerobik. Daya tahan aerobik sering juga disebut dengan daya tahan paru-jantung (cardiovaskuler). Menurut
Analisis data menggunakan statistik deskriptif.

\section{Hasil Penelitian dan Pembahasan Hasil Penelitian}

Setelah dilakukan tes dan pengukuran, maka didapatkan data dalam penelitian ini sebagai berikut: 
sepak bola berlangsung, sehingga tujuan permainan sepak bola sulit untuk dicapai.

Berdasarkan analisis dan olahan data dari 25 orang atlet yang dijadikan sebagai sampel dalam penelitian ini, maka didapatkan 3 orang (12\%) memiliki daya tahan aerobik 54,88 - 57,90 tergolong sedang. Sesuai wawancara peneliti dengan pelatih dan atlet tersebut setelah melakukan tes bahwasanya 3 atlet tersebut memang termasuk atlet yang rajin latihan. Mungkin itulah salah satu faktor yang membuat mereka beda dengan atlet yang lain sehingga bisa mencapai daya tahan aerobik dalam kategori sedang. Meskipun belum dalam kategori baik mungkin dengan penambahan latihan yang terarah dari pelatih yang memfokuskan pada kemampuan daya tahan aerobik, 3 atlet tersebut bisa mencapai dengan cepat dari atlet-atlet yang lain.

12 orang $(48 \%)$ memiliki daya tahan aerobik 51,52 - 54,54 tergolong kategori kurang. Atlet dalam kategori kurang ini memang ada beberapa faktor yang membuat mereka memliki daya tahan aerobik kategori kurang. Sesuai dengan yang di katakan pelatihnya bahwa atlet tersebut malas latihan dan sering terlambat, butuh latihan khusus yang diberikan pelatih untuk membuat para atlet ini bisa memiliki daya tahan aerobik dalam kategori baik. Di samping itu kesadaraan atlet juga sangat dibutuhkan agar di setiap latihan mereka bisa mengikuti dengan baik dan disiplin.

10 orang $(40 \%)$ memiliki daya tahan aerobik <51,52 tergolong kurang sekali. Atlet dalam kategori kurang sekali ini memang atlet yang tingkat disiplinnya sangat rendah. Sesuai diskusi yang peneliti lakukan dengan pelatih di lapangan, banyak faktor yang menyebabkan para atlet ini memiliki tingkat daya tahan aerobik yang buruk. Selain dari rendahnya tinggkat disiplin saat latihan, mereka juga kurang disiplin di dalam menerapkan budaya hidup sehat diantaranya seperti, merokok, suka bergadang, sering main ke warnet tanpa memikirkan waktu, dan lain-lain. Diharapkan kepada pelatih untuk bisa menyadarkan para atlet tersebut agar permasalahan yang dibawas di atas tidak berkelanjutan dan mereka harus dibina secara khusus agar bisa mengikuti latihan dengan baik. Peran orang tua juga sangat penting untuk bisa mengontrol anakanaknya dengan baik agar perubahan dalam meningkatkan daya tahan aerobik yang baik bisa terwujud.

Sedangkan untuk kategori sempurna, baik sekali, dan baik tidak ada $(0 \%)$. Rata-rata daya tahan aerobik yang dimiliki atlet Sekolah Sepak Bola Global usia 14-16 tahun kota Payakumbuh yaitu 51,44 , tergolong dalam kategori kurang sekali. Akibatnya atlet tidak dapat bertahan cukup lama dalam pertandingan yang mengakibatkan mereka sering mengalami kekalahan yang berdampak pada penurunan prestasi. Selanjutnya, akibat atlet tidak memiliki daya tahan aerobik yang baik, dapat menyebabkan penurunan peforma atlet saat menjalani pertandingan yang ditandai dengan atlet terlihat mulai kelelahan, kurang bersemangat, sering terjadi kesalahankeselahan teknik dan menurunya kualitas penampilan atlet sehingga tempo permainan menjadi menurun. Apabila hal ini dibiarakan secara terus-menerus akan mengakibatkan kegagalan dan prestasi optimal sulit untuk diraih.

Oleh sebab itu, daya tahan aerobik atlet perlu ditinggkatkan secara sistematis agar menjadi lebih baik. Untuk meningkatkan daya tahan aerobik banyak metode latihan yang dapat digunakan. Metode-metode tersebut dapat dibedakan berdasarkan tinggi-rendahnya intesitas beban dan durasi lama latihan. Menurut Syafruddin (2016:105) untuk meningkatkan daya tahan aerobik bisa menggunakan latihan seperti : lari jauh dengan intesitas rendah dan konstan, lari naik turun gunung, bersepeda jarak jauh, latihan fartlek. Menurut Morgan dan Anderson dalam Widiastuti (2011:98) daya tahan aerobik bisa ditingkatkan dengan menggunakan metode circuit training terdiri dari latihan kondisi fisik seperti kelincahan, daya tahan, kekuatan, kecepatan dan masih banyak cara metode latihan lain yang dapat digunakan.

Dengan diketahuinya kemampuan daya tahan aerobik atlet Sekolah Sepak Bola Global usia 14-16 Tahun Kota Payakumbuh dengan kategori kurang 
sekali, maka diharapkan kepada pelatih untuk memberikan latihan-latihan yang dapat meningkatkan daya tahan aerobik. Di samping itu, atlet juga diharapkan untuk bisa bersikap serius dan disiplin dalam mengikuti latihan. Apabila atlet sudah memiliki kemampuan daya tahan aerobik yang baik maka seorang atlet tersebut akan bisa mengaplikasikan teknik dan taktik yang dia kuasai di lapangan sehingga prestasipun akan mudah untuk diraih.

\section{Simpulan dan Saran}

Berdasarkan hasil penelitian yang telah diuraikan pada bab terdahulu, dapat dikemukakan kesimpulan bahwa daya tahan aerobik atlet Sekolah Sepak Bola Global usia 14-16 tahun kota Payakumbuh dari 25 pemain adalah 3 orang $(12 \%)$ memiliki daya tahan aerobik 54,88-57,90 tergolong sedang, 12 orang $(48 \%)$ memiliki daya tahan aerobik 51,52-54,54 tergolong kategori kurang, dan 10 orang $(40 \%)$ memiliki daya tahan aerobik <51,52 tergolong kurang sekali. Rata-rata daya tahan aerobik yang dimiliki atlet Sekolah Sepak Bola Global usia 14-16 tahun Kota Payakumbuh yaitu 51,44. Hal ini menunjukkan bahwa tingkat kemampuan daya tahan aerobik atlet Sekolah Sepak Bola Global usia 1416 tahun kota Payakumbuh tergolong dalam kategori kurang sekali.

Berdasarkan hasil penelitian dan kesimpulan di atas, maka penulis dapat memberikan saran-saran diantaranya, kepada manager agar memperhatikan sarana prasarana dan kualitas pelatih agar proses latihan berjalan dengan lancar, sehingga permasalahan yang terjadi dalam tim bisa di atasi dengan baik seperti permasalahan daya tahan aerobik atlet Sekolah Sepak Bola Global usia 1416 tahun kota Payakumbuh. Kepada pelatih untuk dapat memperhatikan daya tahan aerobik yang ada saat sekarang agar dapat ditingkatkan dengan memberikan latihan yang memfokuskan pada peningkatan daya tahan aerobik agar menjadi lebih baik. Kepada orang tua agar bisa mengontrol anak-anak mereka supaya terhindar dari lingkungan yang bisa membuat anak mereka terkena dampak negatif yang bisa mempengaruhi kondisi fisiknya. Kepada atlet untuk dapat meningkatkan kemampuan daya tahan aerobik dan menghindari pola hidup tidak sehat yang bisa mempengaruhi daya tahan aerobik mereka. Kepada peneliti selanjutnya ini hanya terbatas pada tingkat daya tahan aerobik atlet Sekolah Sepak Bola Global usia 14-16 tahun kota Payakumbuh, untuk itu disarankan perlu dilakukan penelitian pada komponen kondisi fisik yang lainya atau komponen teknik.

\section{Daftar Rujukan}

Bafirman. 2010. Pembentukan Kondisi Fisik. Malang : Wineka Media.

Deswandi.2015. "Perbedaan Dampak Olahraga Aerobik dan Anaerobik Terhadap VO2MAX dan Denyut Nadi Istirahat Pada Atlet”. Penelitian Madya. Hlm. 1-58.

Irianto, Djoko Pekik. 2004. Bugar dan Sehat dengan Berolahraga. Yogyakarta : C.V Andi Offset.

Luxbacher, joseph A.(2011) Sepak Bola. Jakarta : PT. Raja Grafindo Persada.

Santoso, Nurhadi. 2014. "Tingkat Keteraampilan Passing-Stoping Dalam Permainan Sepak Bola Pada Mahasiswa PJKR B Angkatan 2013”. Jurnal PJI. Nomor 2. Hlm. 40-48.

Suwirman. 2015. Dasar-Dasar Penelitian. Padang : Fakultas Ilmu Keolahragaan Universitas Negeri Padang.

Syafruddin. 2016. Perangkat Pembelajaran Ilmu Melatih Dasar (Prestasi, Kebugaran, Kesehatan). Padang : FIK UNP.

Tim Mata KuliahStatistik. 2017. Silabus Dan Handout Mata KuliahStatistik 2.Padang

:FakultasIlmuKeolahragaanUniversita sNegeri Padang.

Umar. 2014. Fisiologi olahraga. Padang : UNP Press.

Widiastuti. 2012. Tes Dan Pengukuran Olahraga. Jakarta : PT Bumi Timur Raya

Yulifri. 2012. PermainanSepak Bola. Padang : Universitas Negeri Padang. 